\title{
Biorefinaria - Desenvolvimento de Plataformas Químicas através de Tecnologias Integradas de Biomassa
}

\author{
Matéria baseada no Workshop promovido pela Associação Brasileira de Polímeros - ABPol em 3 de fevereiro de 2009, \\ sobre Biorefinery, apresentado pelo Prof. Mohini M. Sain da Universidade de Toronto, Canadá.
}

Revisão e adaptação, Muhammad Pervaiz e Carlos A. Correa

\section{Introdução}

O início do século 21 tem-se caracterizado por um grande interesse na utilização de matérias-primas de fontes renováveis para geração de inúmeros produtos de interesse tecnológico, incluindo componentes químicos básicos essenciais. (Nota do tradutor: Chemical Building blocks: SPONCH: Enxofre; Fósforo; Oxigênio; Nitrogênio, Carbono e Hidrogênio; Macromolecular Building Blocks: carbohidratos, lipídios, proteínas, e ácidos nucleicos). Todavia, a conversão industrial sustentável de biomassa em produtos com alto valor agregado ainda necessita da reestruturação parcial ou mesmo completa de toda economia baseando-se em novos métodos de pesquisa e desenvolvimento. Uma nova abordagem consiste no desenvolvimento de tecnologias para biorefinarias e sistemas que são similares à refinaria de petróleo e involvem processos de conversão integrada de biomassa e equipamentos para produção de combustíveis, energia e produtos químicos basebio.
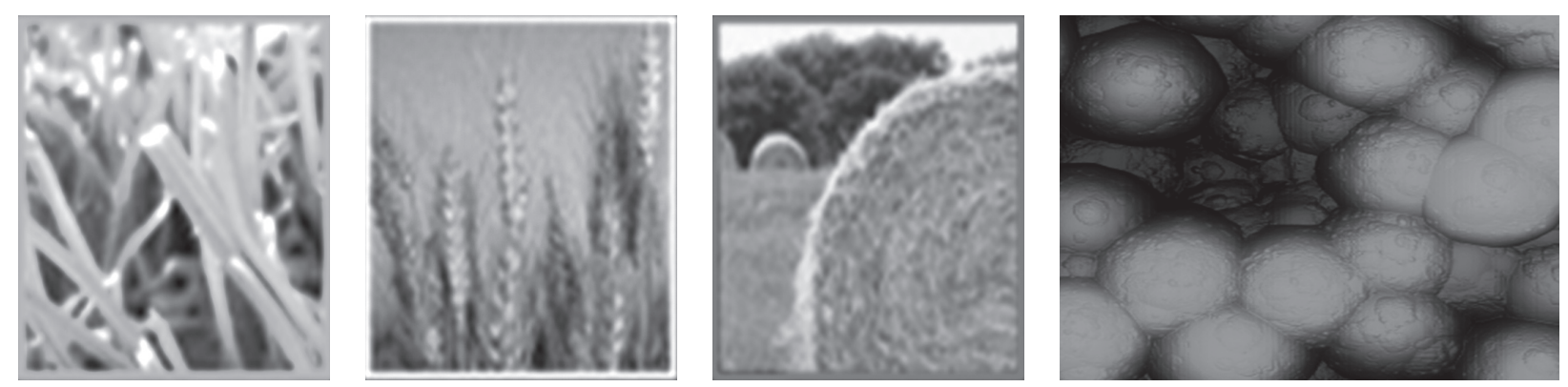

\section{Matérias-Primas Basebio e Tecnologias de Conversão}

Convencionalmente usinas de processamento de polpa de celulose/papel e milho por via úmida podem ser consideradas como biorefinarias uma vez que estas produzem uma infinidade de produtos basebio como matéria-prima. As pesquisas atuais nesta área concentram-se no fomento de novas indústrias para converter biomassa em uma variedade de produtos, incluindo aqueles que possam eventualmente vir a substituir produtos de origem petroquímica. Duas das mais promissoras plataformas emergentes em biorefinaria são as plataformas de açúcar e a plataforma termoquímica ${ }^{[1]}$. Biorefinarias de plataformas de açucar convertem biomassa em diferentes tipos de açúcares por fermentação ou outro processo biológico em várias plataformas químicas e/ou combustíveis. Por outro lado, as biorefinarias termoquímicas podem converter biomassa em syngas (synthetic natural gas) com precursor do biodiesel.

\section{Desenvolvimentos Recentes: Foco em Plataformas Químicas}

As previsões atuais indicam que por volta de 2025, mais de 30\% das matérias-primas para a indústria química serão produzidas a partir de fontes renováveis ${ }^{[2]}$. Para se atingir tais metas, são indispensáveis os desenvolvimentos de novas tecnologias para plataformas de biorefinarias, tais como biorefinarias para conversão de matérias-primas a base de lignocelulósicos (LFC) com ênfase na separação eficiente do (LFC) em lignina, celulose e hemicelulose. Outras grandes áreas de intensa atividade de pesquisa são os avanços em processos térmicos, químicos, mecânicos e biológicos. A próxima geração de biorefinarias também conhecida como biorefinarias fase III, também está no topo da lista nas agendas de pesquisa, as quais irão facilitar a verdadeira integração das diferentes matérias-primas e tecnologias para o desenvolvimento de uma variedade de produtos customizados. Embora produtos ditos funcionais, como materiais compósitos reforçados com fibras e produtos derivados de amido/proteínas, já sejam obtidos atualmente de fontes renováveis e inclusive podem ser encontrados no mercado, as pesquisas atuais estão focadas no desenvolvimento de plataformas químicas e syngas (synthetic gas) para desenvolvimento consistente de compostos estruturados como componentes químicos básicos essenciais para indústria.

O Departamento Norte-Americano de Energia finalizou uma lista de doze potenciais plataformas químicas basebio obtida a partir da análise de cerca de 300 substâncias baseadas em precursores de biomassa (carbohidratos, ligninas, gorduras e proteínas), plataformas de processos, componentes básicos, e aplicação final ${ }^{[3]}$.

Estas doze plataformas químicas base-açucar com grupos funcionais múltiplos, como mostrados na Figura 1, podem ser produzidos biologicamente ou quimicamente a partir de 


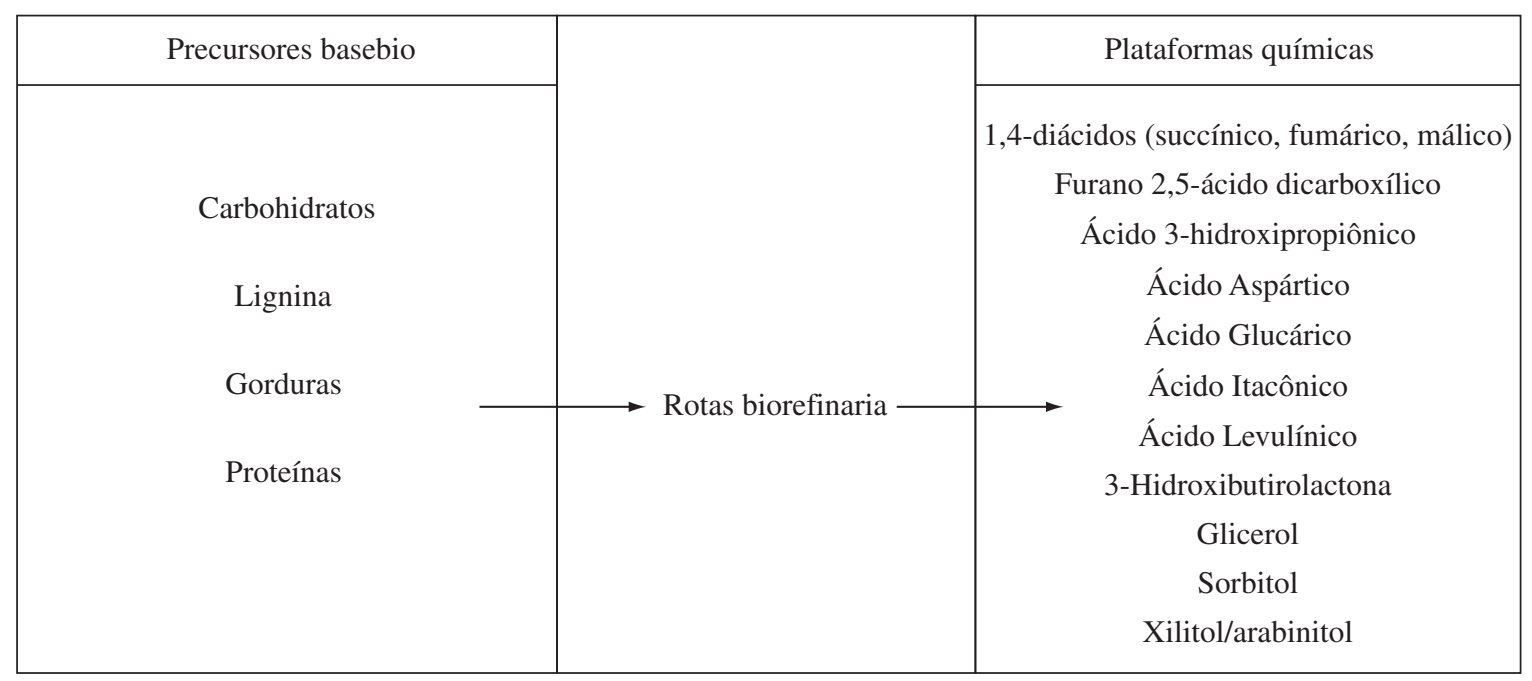

Figura 1. Principais plataformas químicas relacionadas pelo Departamento de Energia Norte-Americano ${ }^{[3]}$.

açucares e convertidos posteriormente em uma variedade de produtos químicos e materiais basebio de elevado valor. Um método para degradação da hiper-funcionalidade (Mudanças de propriedades devido a pequenas alterações conformacionais) em carbohidratos são processos catalizados por ácidos para remoção seletiva de grupos funcionais e formação de componentes básicos definidos, tais como os aldeídos furânicos, furfural (F) e 5-hidroximetil-furfural (HMF) que podem ser produzidos a partir de inulina (um polissacarídeo da frutose) por desidratação intramolecular catalizada por ácidos, e convertida em ácido 2,5-dicarboxílico furano (FDCA) por oxidação seletiva o qual é precursor de vários outras plataformas químicas de alto valor, tais como poli(tereftalato de etileno) e poli(tereftalato de butileno ${ }^{[4,5]}$. A redução do HMF pode gerar posteriormente 2,5-dihidroximetila furano e 2,5-bis(hidroximetila) tetrahidrofurano, alcoois essenciais para o completo desenvolvimento de polímeros basebio.

Tratamentos hidrotérmicos também conhecidos como tecnologia de autohidrólise, são utilizados na hidrólise seletiva da hemicelulose e tem sido considerada recentemente como rota alternativa para isolamento dos principais contituintes da LCF. À parte dos benefícios, tais como baixo custo e minimização de problemas de corrosão, a autohidrólise possue uma ampla variedade de aplicações incluindo os estudos cinéticos para maximizar a concentração oligômeros de açúcares a partir da celulose de madeira ${ }^{[6]}$.

\section{Exemplos Comerciais}

\section{Codexis Inc/Cargill: 3-HP}

A Cargill em colaboração com a Codexis, Inc., um empresa líder em tecnologia de evolução de DNA, e o Pacific Northwest National Laboratory (PNNL), desenvolveram uma nova plataforma tecnológica basebio que permite a geração de uma variedade de produtos derivados do ácido 3-hidroxipropiônico (3-HP). O cerne desta plataforma tecnológica consiste na fermentação de carbohidratos para produção do 3-HP, o qual pode ser convertido em outros im- portantes produtos químicos tais como ácido acrílico e seus derivados, 1,3-propanodiol, plásticos baseados em 3-HP, e vários outros produtos de elevado valor ${ }^{[7]}$.

\section{DuPont, USA: Sorona ${ }^{\circledR}$}

O componente chave do Sorona ${ }^{\circledR}$ é o Bio-PDO ${ }^{\mathrm{TM}}$, o qual é obtido do açúcar de milho utilizando um processo de fermentação desenvolvido e patenteado pela Dupont. O Bio-PDO ${ }^{\mathrm{TM}}$ é um substituto para o derivado petroquímico 1,3-propanodiol (PDO) e/ou 1,4-butanodiol (BDO). DuPont ${ }^{\mathrm{TM}}$ Hytre $^{\circledR}$ obtido a partir de fontes renováveis será produzido utilizando o novo poliol Bio-PDO ${ }^{\mathrm{TM}}$. O Sorona ${ }^{\circledR}$ da DuPont ${ }^{\mathrm{TM}}$ veem sendo utilizado em fibras, tecidos, filmes, filamentos, components de engenharia e resinas. O Hytrel $^{\circledR}$ DuPont $^{\mathrm{TM}}$, representa uma nova classe de termoplásticos de engenharia basebio ${ }^{[8]}$.

\section{Pacific Northwest National Laboratory/Biofine Corporation: Ácido Levulínico}

Um processo catalítico para a produção do tetrahidrofurano de metila foi desenvolvido pelo Pacific Northwest National Laboratory e licenciado para a Biofine Corporation para utilização na tecnologia de produção do ácido levulínico. The processo da Biofine converte de maneira econômica material-prima celulósica basebio em ácido levulinic. Uma vez limitado a aplicações em especialidades de alto valor, tais como poliamidas, borrachas e produtos farmacêuticos, esta plataforma química também pode ser convertida em uma variedade de produtos químicos, incluindo a substitução direta de derivados petroquímicos, tais como Tetrahidrofurano de metila, um aditivo oxigenado para combustíveis que vem se tornando muito importante ${ }^{[9]}$.

\section{Applied CarboChemicals, Inc.: Ácido Succínico (Ácido butanodióico)}

Outro processo desenvolvido pelo Pacific Northwest National Laboratory converte milho em fontes econômicas e ambientalmente corretas para produção de polímeros, fibras para vestuário, solventes, tintas, aditivos alimentícios, parachoques de automóveis, e uma gama de produtos industriais e 
de consumo. Conhecido como processo BDSA (Ácido succínico de origem biológica), utiliza-se novos microorganismos na fermentação e uma nova tecnologia de catálise na etapa de maior valor. Esta tecnologia foi licenciada para a Applied CarboChemicals Inc, para aplicações comerciais ${ }^{[10]}$.

\section{Cargill Dow LLC: Poli(ácido láctico)(PLA)}

O polímero Poli(ácido láctico) (PLA) da Cargill Dow LLC, também conhecido como PLA NatureWorks ${ }^{\mathrm{TM}}$ é um termoplástico produzido a partir da fermentação de açucares de biomassa. O produto da fermentação, o ácido láctico é convertido em lactideo que é purificado e polimerizado utilizando um processo especial de abertura de anel. A planta indutrial possui uma capacidade de $140 \mathrm{kton} / \mathrm{ano}$ e a demanda pelo PLA da NatureWorks tem sido tão elevada que a Cargill Dow projeta um provável mercado de 3.6 millhões de toneladas para $2020^{[11,12]}$.

\section{Metabolix/Monsanto: Polihidroxialcoanatos - PHAs}

Na década de 90, a fermentação bacteriana dos PHAs, mais especificamente a do poli(3-hidroxibutirato-co-3-hidroxivalerato) (PHBV), foi desenvolvida comercialmente por Zeneca e pela Monsanto sob a marca Biopol ${ }^{\mathrm{TM}}$. Todavia, os custos de produção do PHBV mostraram-se elevados (mais de US\$ 6.60/kg) e, portanto muito pouco competitivo como os petroplásticos convencionais. Desde então, a Metabolix desenvolveu uma tecnologia de fermentação de baixo custo para a produção de PHAs, que segundo a empresa permitira uma produção em escala comercial abaixo de US\$2.20/ $\mathrm{kg}^{[13]}$. Um custo de produção a este nível poderia abrir um mercado significativo para os PHAs base-fermentação.

\section{DuPont/Genencor: 1,3-propanodiol}

Juntamente com o ácido tereftálico purificado, o 1,3-propanodiol é utilizado na produção do poli(tereftalato de trimetileno) (PTT), um polímero com propriedades de estiramento-recuperação surpreendentes. Recentemente, através de uma parceria com a Genencor International, a DuPont desenvolveu uma rota de fermentação de baixo custo que converte açúcares de biomassa em 1,3-propanodiol ${ }^{[14]}$. O PTT é utilizado em roupas esportivas, tapeçarias, resinas especiais e outras aplicações nas quais propriedades como maciez, conforto, tingimento e fácil manutenção são altamente desejáveis. As propriedades do PTT superam a das poliamidas e poliésteres alifáticos nas aplicações de fibras, e a do PBT e PET em muitas aplicações de engenharia.

\section{Referências}

1. National Renewable Energy Laboratory, Biomass Program, June 2006. http://www.nrel.gov/biomass/biorefinery.htm.
2. European Technology Platform for Sustainable Chemistry, Industrial Biotechnology Section, 2005, http:// www.suschem.org.

3. Top Value Added Chemicals from Biomass (Eds.: T. Werpy, G. Petersen) [US Department of Energy, Office of Scientific and Technical Information, No. DOE/GO-102004-1992, http://www.nrel.gov/docs/ fy04osti/35523.pdf], (2004).

4. "New Developments in the Use of Sucrose as an Industrial Bulk Chemical": H. Schiwek, M. Munir, K. M. Rapp, B. Schneider, M. Vogel in Carbohydrates as Organic Raw Materials (Ed.: F.W. Lichtenthaler), VCH, 1991, pp. 57-94.

5. Production of Platform Chemicals and Synthesis Gas from Biomass, B. Kamn, Angew. Chem. Int. Ed., 46, p.5056-5058, (2007).

6. Biorefinery: Conversion of Woody Biomass to Chemicals, Energy and Materials, Thomas E. et al, Journal of Biobased Materials and Bioenergy, 2, p.100-120, (2008).

7. US Depertment of Energy. Biomass Program. A New Biorefinery Platform Intermediate. http://www1.eere. energy.gov/biomass/.

8.http://www2.dupont.com/Sorona/en_US/uses_apps/ uses_apps_home.html.

9. Success Story; Conversion of Biomass Wastes to Levulinic Acid and Derivatives http://www.pnl.gov/biobased/docs/mthf.pdf.

10. Production of Chemicals from Biologically Derived Succinic Acid (BDSA) http://www.pnl.gov/biobased/ docs/succinic.pdf

11. Dow, LLC. "NatureWorks TM PLA," http://www.cargilldow.com/ corporate/natureworks.asp.

12. Fahey, J. (2001), Forbes Magazine, November 26, p.206.

13. Metabolix, Inc. "Biotechnology Foundation: Plants," http://www.metabolix.com/biotechnology\%20foundation/plants.html.

14. PR Newswire. Copyright@ 2007 http://www.bio-medicine.org/biology-technology-1/DuPont--GenencorInternational-and-Tate--26-Lyle-Honored-for-Groundbreaking-Work-in-Developing-Bio-PDO-28TM-29224-2. 